\title{
MOLECULAR DETECTION OF TTV DNA IN CHRONIC HEPATITIS PATIENTS FROM A HOSPITAL IN KERMAN, IRAN
}

\author{
Arabzadeh S.M. ${ }^{1}$, Zahedi M.J. ${ }^{*}$, Mollaie H.R. ${ }^{3}$, Aghaie Afshar A. ${ }^{3}$ Iranmanesh Z. ${ }^{3}$ \\ 1- Kerman School of Medicine, 2- Kerman School of Medicine, 3- Department of medical virology, Kerman
}

\begin{abstract}
A novel human DNA virus, TT virus (TTV), was first discovered in the sera of three Japanese patients with post transfusion hepatitis in 1997. TTV is a non-enveloped, single stranded virus related to the Circoviridae family. TT virus DNA was investigated in serum samples of 100 patients with various types of chronic hepatitis, and 100 healthy subjects from Kerman, Iran by nested PCR using the primers that belonged to UTR (A) region of the genome. Serum levels of alanine aminotransferase (ALT) and aspartate aminotransferase (AST) were also determined. TTV DNA was detected in $4 \%$ of healthy population, $12 \%$ of type-B hepatitis patients, and $21 \%$ of type$C$ hepatitis patients with liver disease. TTV infections are more frequently found in patients infected with hepatitis B virus (HBV) or hepatitis C virus (HCV) than general population. However, no significant association between TTV infection and liver injury has been reported.
\end{abstract}

Keywords: • Transfusion Transmitted virus (TTV) • PCR • type B hepatitis • type C hepatitis

\section{Introduction}

$\mathrm{T}$ $\mathrm{T}$ virus (TTV) is a newly described DNA virus that was first detected in the blood of three patients with elevated serum aminotransferases following transfusion; however the patients tested negatively for known hepatitis viruses. The virus has been found worldwide with a high prevalence in general population. However, accumulating evidence suggests that the virus is not a significant cause of acute or chronic liver disease. To date no other disease associations with TTV infection have been described (1). After the discovery of the hepatitis A and B viruses in the 1960s and 1970s, it became apparent that an unidentified agent was responsible for hepatitis in a number of patients suspected of having acute or chronic viral hepatitis. The unknown pathogen was referred to as non-A non-B hepatitis until the hepatitis $\mathrm{C}$ virus (HCV) was identified in 1989 and was found to account for hepatitis in the majority of these patients. However, in approximately $5 \%$ of patients with liver disease, no causative agent can be identified (2). It has long

*Corresponding Author: Zahedi M.J.

Kerman School of Medicine been suspected that additional hepatotropic viruses will be discovered to account for some of these cases, especially since approximately half of these patients have a history of blood transfusion $(2,3)$. Hepatitis G virus, identified in 1996, has proven to be an unlikely candidate since an association with hepatitis or any other disease has not been consistently demonstrated (3). A novel virus associated with post transfusion hepatitis was identified in 1997 in three patients from Japan who developed elevated serum aminotransferase levels following transfusion and tested negatively for all known hepatitis viruses (4). The virus (referred to as TT virus for the initials of the patient in whom it was isolated or "transfusion transmitted virus" [TTV]) exhibited hepatotropism, and its titers correlated with elevation in serum aminotransferase levels suggesting that it was a true hepatitis virus. However, the role of TTV in pathogenicity of liver remains uncertain.

\section{MATERIALS AND METHODS}

\section{Patients}

A total of 100 consecutive patients with biopsy proven chronic hepatitis, who visited the Out Patient Clinic of Afzalipoor Hospital, Kerman, 
between April 2006 and May 2007, were included in the study. The patients were diagnosed as having hepatitis due to HBV, or HCV based on polymerase chain reaction (PCR) technique .The chronic state of the disease was determined by conventional clinical, biochemical and histological methods. The mean duration of the disease was 10 \pm 6 months. Anti-HCV or HBsAg positive patients with persistently elevated alanine amino transferase (ALT) levels (>70 IU/l), detectable HCV RNA or HBV DNA in serum, and a liver biopsy that indicates either portal or bridging fibrosis or at least moderate degree of inflammation and necrosis were included under HCV or HBV related chronic hepatitis categories. Patients with autoimmune liver disease, druginduced hepatitis and alcohol related injuries were excluded. A group of 100 patients (chronic non-B, non-C hepatitis) were seronegative for both HBV and $\mathrm{HCV}$ markers as revealed by ELISA and PCR studies. History of blood transfusion (HBT) was recorded in 6 patients in this group. Another group of 50 patients (chronic hepatitis B) was seropositive for HBsAg and HBV DNA and seronegative for anti-HCV and HCV RNA. Twelve patients had HBT in this group. A total of 50 patients (chronic hepatitis $\mathrm{C}$ ) were seropositive for anti-HCV and HCV RNA and seronegative for HBsAg and HBV DNA. Fourteen patients in this group had HBT. The healthy controls $(n=100)$ were drawn from healthy men and women voluntary blood donors with normal liver function test (LFT) profiles and negative serology test results, for HBV and HCV. Twenty five individuals had HBT in this group.

\section{Serology}

Serum samples collected from all 100 chronic hepatitis patients and 100 healthy control subjects were included for serological tests for hepatitis B and $\mathrm{C}$ viruses. Enzyme Linked Immunosorbent Assay (ELISA) for detection of $\mathrm{HBs} \mathrm{Ag}$ was carried out by using commercial ELISA kit (RADIM, Italy). Third generation ELISA kits were used for detection of antibody to HCV (RADIM, Italy). The analysis was based on the 200 patients using SPSS 11.5 for Windows software (SPSS Inc. Chicago, Illinois, USA). Prevalence and 95\% confidence intervals $(95 \% \mathrm{CI})$ were calculated.

\section{Molecular Test}

Five $\mathrm{ml}$ of blood sample was collected from each patient in a sterile container with $100 \mu \mathrm{l}$ EDTA 0.5
$\mathrm{M}$ and mixed. Plasma was separated and stored at $-80^{\circ} \mathrm{C}$ for further testing. Plasma samples of HCV or HBV patients were obtained from Afzalipoor hospital in Kerman, Iran. The 100 samples were confirmed to be HCV or HBV positive by PCR and RT-PCR Method. This test is a routine work in our laboratory for detection of $\mathrm{HCV}$ and $\mathrm{HBV}$. Fifty samples were HCV Positive and 50 samples were HBV positive, however 8 samples were both $\mathrm{HCV}$ and HBV Positive. Viral DNA was extracted from $200 \mu 1$ plasma by using QIAmp blood mini kit (QIAGEN, Germany) and resuspended in 50 $\mu 1$ elution buffer.

DNA was stored at $-80^{\circ} \mathrm{C}$ for further testing. All samples were tested for the presence of TTV DNA By semi-nested PCR. The method of PCR was performed using specific primers for the 5'-UTR genome regions in all samples, and this region is highly conserved in the TTV (5).

\section{PCR Protocol}

Five $\mu 1$ of extracted DNA sample was added to 25 $\mu 1$ of reaction mixture containing 5 units Taq polymerase, $0.01 \%$ gelatin, $0.6 \mu \mathrm{M}$ of each primer, $200 \mu \mathrm{M}$ of each deoxynucleotid triphosphate, $5 \mu 1$ of reaction buffer $(50 \mathrm{mM} \mathrm{KC1}, 10 \mathrm{mM}$ tris-HCI, $\mathrm{pH}=8.3)$ and $1.5 \mathrm{mM} \mathrm{MgCl} 2$. TTV DNA was determined by semi-nested PCR using primers generated from the conserved region of the TTV genome. The first round PCR was carried out with $5 \mu 1$ of the extracted DNA using 10 pmol primer A (sense: 5-ACA GAC AGA GGA GAA GGC AAC ATG-3) and 10 pmol primer B (antisense: 5CTGGCATTT TAC CATTTCCAAAGT T-3) for 35 cycles at $94{ }^{\circ} \mathrm{C}$ for $30 \mathrm{sec}, 58{ }^{\circ} \mathrm{C}$ for $30 \mathrm{sec}, 72$ ${ }^{\circ} \mathrm{C}$ for $30 \mathrm{sec}$ with additional $7 \mathrm{~min}$ for a final extension step at $72{ }^{\circ} \mathrm{C}$. The second-round PCR was performed with $2 \mu \mathrm{l}$ of the product of the firstround PCR using another sense primer $\mathrm{C}$ (5-GGC AAC ATG TTA TGG ATA GAC TGG-3) and primer $\mathrm{B}$ for 25 cycles under the same conditions. Amplification product of the second-round PCR (272 base pairs) was electrophoresed in $2 \%$ agarose gel with proper markers (100bp Roche, Germany), stained with ethidium bromide, and visualized under UV light. Standard precautions were taken to avoid sample-to-sample contamination and PCR product carryover (figure1). 


\section{Results}

In this study, 100 patients with $\mathrm{HBs} \mathrm{Ag}$ positive and Anti-HCV positive And 100 subjects from general population were tested for TTV DNA by PCR. Thirty seven out of $200(18.5 \%)$ were positive for TTV DNA. The result was confirmed twice by PCR. The prevalence of TTV DNA observed was $18.5 \%$ in our study. Twelve out of 50 samples that were HBs Ag positive, were also positive for TTV DNA (24\%). Twenty out of 50 samples that were Anti-HCV positive, were also positive for TTV $(42 \%)$. Also four samples were positive for HBs Ag, Anti-HCV and TTV DNA .

The study group consisted of 200 Subjects (120 males and 80 females; mean age: 50 years; range: 35 and 65 years) with chronic HBV or HCV infections. The diagnosis of chronic hepatitis was made on the basis of clinical and histological results.

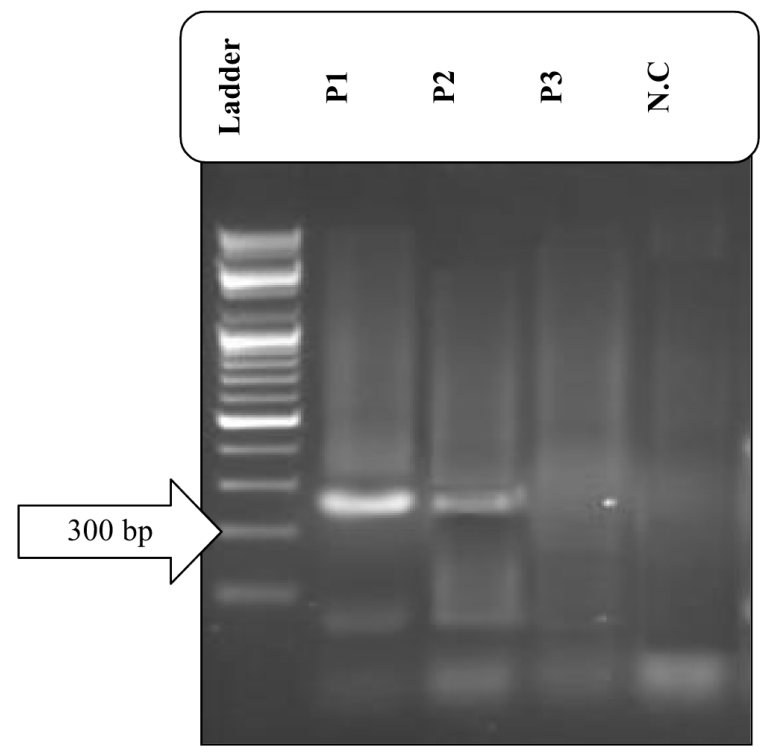

Figure1: TTV PCR Agarose Gel electrophoresis Ladder: MW marker (100bp),

P1: type-B hepatitis that TTV PCR was positive,

P2: type-C hepatitis that TTV PCR was positive,

P3: subject that TTV PCR was Negative,

N.C: Negative control

The age distribution between TTV-positive and TTV-negative patients did not differ significantly. The proportion of patients with blood transfusion histories was higher in the TTV-positive group than in TTV-negative group. The sex distribution was not significantly different between TTVpositive and TTV-negative groups. To evaluate the correlation between TTV infection and hepatic damage, the serum levels of ALT and AST were measured in all subjects (data not shown). No significant increase in serum ALT and AST was observed in TTV positive Subjects, compared with TTV negative subjects. In addition, TTV coinfection did not elicit any further significant increase in ALT and AST levels in patients with chronic liver disease. Furthermore, no increase in ALT and AST was observed in HBV or HCV positive patients. These observations suggested that there is no significant association between TTV infection and hepatic injury in our study subjects.

TTV DNA was detected in 12 of 50 patients (24\%) with type-B hepatitis, 21 of 50 patients $(21 \%)$ with type-C hepatitis patients, and 4 of 100 healthy subjects $(4 \%)$ with normal liver function profile tests. The prevalence of TTV was significantly higher in type-B hepatitis patients and type-C hepatitis patients as compared with normal subjects (Table 1). Among 100 samples which were positive for HBV and HCV four of the samples were positive for all three viral markers (HBV, HCV, and TTV DNA).

Table 1: The prevalence of TTV infection

\begin{tabular}{cll}
\hline Subject & $\mathbf{n}$ & TTV (\%) \\
\hline General population* & 100 & $4(4 \%)$ \\
\hline Type-B hepatitis patients & 50 & $12(24 \%)$ \\
\hline Type-C hepatitis patients & 50 & $21(42 \%)$ \\
\hline Total & 200 & $37(18.5 \%)$
\end{tabular}

*General population: Non B-Non C hepatitis

\section{Discussion}

In the present study, the prevalence of TTV in patients with chronic liver diseases $(33 \%)$ was found to be higher than to that in healthy blood donors (4\%). Arankalle et al reported TTV positivity only in HBV DNA positive subject of chronic hepatitis patients. However, detailed clinical data of the patients like age, sex, history of blood transfusions were not studied. Several studies have revealed high (1.9 to 36\%) TTV DNA prevalence in healthy control groups (7).

TTV may be acquired early in life, particularly in countries with a high prevalence of viral infection in the general population. A series from Japan found that $5 \%$ of 197 children referred to a general 
pediatric center had TTV DNA detectable in their serum (6). In another report from the Democratic Republic of Congo, TTV was found in 61 out of 105 women $(58 \%)$ attending an antenatal clinic and 36 of $68(54 \%)$ of their infants (8). The virus can be detected in the stool and bile of infected patients, suggesting that it may be transmitted by enteric rout $(9,10)$. A high prevalence of infection has been found in patients with parenteral exposure to blood. TTV DNA was detected in $44 \%$ of patients with hemophilia in the United Kingdom (11), and up to $75 \%$ in Japan $(12,13)$. A report from China found a prevalence of $22 \%$ among those with a history of intravenous drug use (14). TTV was present in $84 \%$ of Italian patients with transfusion-dependent beta thalassemia (15).

Elevated serum ALT levels have been found in 2$5 \%$ of patients with an Anti-HCV positive status, but chronic $\mathrm{HCV}$ infection has a fluctuating course, thereby causing fluctuations in ALT levels. Therefore patient with normal ALT levels may, in fact, have severe histological lesions in liver. In this study, statistically no significant correlation was found between TTV infection and, age, sex or elevated ALT among positive samples.

Choosing the most efficient set of primers for the amplification of a viral nucleic acid is important when testing serum samples. In this study amplification of TTV DNA was carried out with three different sets of primers. A different PCR sensitivity depending on the Region amplified was observed when testing plasma. The set of primers were derived from the 5'-UTR region that was highly conserved.

Preliminary reports in patients who have been followed longitudinally have suggested a low rate of viral clearance. As an example, TTV DNA remained persistently detectable for 3 year in a cohort of 19 patients (16). In another report, 97\% of 93 patients who were followed for 3 years remained infected (15). A third series suggested an annual clearance rate of approximately $7 \%$ (17). However, many of the patients in these series had exposure to blood products. Thus, the extent to which the persistence of TTV DNA represents chronic infection by a single genotype or the acquisition of new genotypes remains uncertain. Our findings indicated that TTV DNA is present in patients with acute hepatitis of otherwise unknown etiology, but a correlation of TTV titers and serum aminotransferase concentrations has been inconsistent; Therefore it remains unclear whether the virus was the cause of the liver disease or was an incidental finding $(18,19,20)$.

\section{References}

1 Alter M: Epidemiology of hepatitis C. Hepatology26 : 62S-65S, 1997

2 Kodali V, Gordon S, Silverman A, McCray D: Cryptogenic liver disease in the United States: Further evidence for non-A, non-B, and non-C hepatitis. Am J Gastroenterol 89:1836-1839, 1994.

3 Miyakawa Y, Mayumi M: Hepatitis G virus: A true hepatitis virus or an accidental tourist? N Engl J Med 336:795 -796, 1997.

4 Nishizawa T, Okamoto $H$, Konishi K, Yoshizawa H, Miyakawa Y, Mayumi M: A novel DNA virus (TTV) associated with elevated transaminase levels in posttransfusion hepatitis of unknown etiology. Biochem Biophys Res Commun 241: 92-97,1997.

5 Nadia Campo,Renata Brizzolara, Nicoletta Sinelli,Francesco Torre,Rodolfo Russo,Giacomo Deferrari,Antonino Picciotto. TT Virus and HGV infections in hemodialysis patients.Nephrol Dial Transplant, 2000;15:1823-1826.

6 Goto K, Sugiyama K, Terabe K, Mizutani F, Wada Y: Detection rates of TT virus among children who visited a general hospital in Japan. J Med Virol 57: 405-407,1999.

7 Arankalle VA, Gandhe SS, Deshmukh TM, Chadha MS, Walimbe AM. Prevalence and phylogenetic analysis of TT virus DNA in western India. Clin Diagn Lab Immunol 2000; 7 : 845-9.

8 Davidson F, MacDonald D, Mokili J, Prescott L, Graham S, Simmonds P: Early acquisition of TT virus (TTV) in an area endemic for TTV infection. J Infect Dis 179:1070 -1075, 1999

9 Okamoto H, Akahane Y, Ukita M, Fukuda M, Tsuda F, Miyakawa Y, Mayumi M: Fecal excretion of a nonenveloped DNA virus (TTV) associated with posttransfusion non-A-G hepatitis. J Med Virol56 : 128132,1998 .

10 Ukita M, Okamoto H, Kato N, Miyakawa Y, Mayumi M: Excretion into bile of a novel unenveloped DNA virus (TT virus) associated with acute and chronic non-A-G hepatitis. J Infect Dis 179 : 1245-1247,1999.

11 Irving W, Ball J, Berridge S, Curran R, Grabowska A, Jameson C, Thomson B, Rynder S: Chronic infection with TT virus: Frequency, effect on chronic HCV infection and virus evolutions [Abstract].Hepatology 28:A800, 1998.

12 Fukuda Y, Nakano I, Katano Y, Toyoda H, Ebata M, Nagano K, Morita K, Yokazaki S, Takeuchi M, Hayashi $\mathrm{K}$, Takamatsu J, Hayakawa T: TT virus infection in Japanese hemophilia patients [Abstract].Hepatology 28:A516, 1998

13 Takayama S, Miura T, Matsuo S, Taki M, Sugii S: Prevalence and persistence of a novel DNA TT virus (TTV) infection in Japanese haemophiliacs.Br J Haematol 104:626 -629, 1999

14 Cao K, Mizokami M, Orito E, Ding X, Ge X, Huang G, Ueda R: TT virus infection among intravenous drug users in southwest China [Abstract].Hepatology 28:A517, 1998 


\section{M.J. Zahedi et.al}

15 Prati D, Lin YH, De Mattei C, Liu JK, Farma E, Ramaswamy L, Zanella A, Lee H, Rebulla P, Allain JP, Sirchia G, Chen B: A prospective study on TT virus infection in transfusion-dependent patients with betathalassemia.Blood 93:1502 -1505, 1999.

16 Hada $T$, Cheng J, Fukui $K$, Ohno M, Ohkawa T, Yokoyama Y, Imanishi H, Hara N, Iijima H, Shimomura $\mathrm{S}$, Yamamoto T, Amuro Y, Higashino K: Detection of TTV DNA in sera of patients with chronic liver diseases and interferon efficacy [Abstract]. Hepatology 28:A815, 1998.

17 Yuki N, Kato M, Masuzawa M, Ishida $H$, Inoue $T$, Matsushita Y, Tabata T, Kishimoto H, Yamamoto K, Kaneko A, Michida T, Iyoda K, Sugiyasu Y, Fujii E, Kurosawa K, Ideda M, Sasaki Y, Kasahara A, Hayashi $\mathrm{N}$, Hori M: Clinical relevance of chronic infection with TT virus, a novel hepatitis associated agent in patients on maintenance haemodialysis [Abstract].Hepatology 28:A513, 1998.

18 Tuveri R, Jaffredo F, Pol S, Lunel F, Marcellin P, Delangeau J, Brechot C, Thiers V: Prevalence of TTV viral DNA sequences in patients with acute and chronic liver disease [Abstract]. Hepatology28: A2259,1998.

19 Ikeda H, Takasu M, Inoue K, Okamoto H, Miyakawa Y, Mayumi M: Infection with an unenveloped DNA virus (TTV) in patients with acute or chronic liver disease of unknown etiology and in those positive for hepatitis $\mathrm{C}$ virus RNA. J Hepatol 30:205 -212, 1999.

20 Cleavinger P, Zein N, Freese D, Perrault J, Persing D, Charlton M: Detection of a novel viral agent linked with post transfusion hepatitis (TT virus) in pediatric patients with fulminant hepatic failure [Abstract].Hepatology 28:A2266, 1998.

21 YouLuTuz Y, Matsui A, Mochida S, Fujiwara K: TT virus infection in patients with fulminant hepatitis [Abstract]. Hepatology28 : A2265,1998. 